\title{
PERENUNGAN DIRI DARI SISI PENDEKATAN SENI DALAM 77 TUJU: SIRI INGATAN KEPADA KAWAN KARYA ZAEN KASTURI
}

\section{(Self-Reflection and Arts Approach in 77 Tuju: Siri Ingatan kepada Kawan by Zaen Kasturi)}

\author{
Qurratul 'Ain Abdul Rahim
}

qurratulain010@gmail.com

\author{
Mawar Safei* \\ mawarsafei.@ukm.edu.my_
}

Program Persuratan Melayu, Pusat Bitara Melayu

Fakulti Sains Sosial dan Kemanusiaan, Universiti Kebangsaan Malaysia.

Published online: 9 June 2020

To Cite: Qurratul 'Ain Abdul Rahim dan Mawar Safei. (2020). Perenungan Diri dari Sisi Pendekatan Seni dalam 77 Tuju: Siri Ingatan kepada Kawan Karya Zaen Kasturi. Malay Literature, 33(1), $123-148$.

\begin{abstract}
Abstrak
Artikel ini meneliti kumpulan puisi 77 Tuju: Siri Ingatan kepada Kawan (2015) oleh Zaen Kasturi. Perbincangan ini merungkai kecenderungan Zaen Kasturi yang menganjurkan perihal perenungan diri dengan mengajukan pertanyaan dan persoalan tentang persahabatan. Sisi introspeksi atau muhasabah diri Zaen Kasturi diteliti menerusi sudut pandang teori Pengkaedahan Melayu, diasaskan oleh Hashim Awang. Di bawah Pengkaedahan Melayu, terdapat turut dibahaskan tentang Pendekatan Seni. Ia bertepatan untuk meneliti kekuatan seni Zaen Kasturi yang jelas terlihat melalui aspek diksi dan gaya bahasa metafora dalam karyanya. Pemilihan kata-kata yang cermat oleh Zaen Kasturi dalam menukangi puisi menimbulkan kesan estetika dan "warna bahasa" begitu jelas menandakan identiti Zaen Kasturi sebagai penyair mapan. Mutu gaya bahasa metafora Zaen Kasturi yang tinggi malah kepintarannya mencipta pengucapan
\end{abstract}

(C) Dewan Bahasa dan Pustaka. 2020. This work is licensed under the term of the Creative Commons Attribution (CC BY) (http://creative commons.org/licenses/by/4.0/) 
kalimat baharu serta kiasan asli dan segar menjadi tarikan unik dalam mengetengahkan soal introspeksi. Diksi dan metafora tidak sekadar perhiasan bahasa Zaen Kasturi tetapi bertujuan mengukuhkan rantai hubungan antara kosa kata dan sirat maksud yang ingin disampaikan. Kumpulan puisi ini tidak mengecualikan kepentingan seni dalam berbahagi makna, khasnya isi yang bernilai introspektif.

Kata Kunci: Pengkaedahan Melayu, Pendekatan Seni, Zaen Kasturi, puisi, kosa kata, sirat makna

\begin{abstract}
This paper examines a collection of poems titled 77 Tuju: Siri Ingatan kepada Kawan [77 Aims: Reminders for Friends Series](2015) by Zaen Kasturi. This discussion underscores Zaen Kasturi's tendency to advocate for introspection by asking questions about friendship. Zaen Kasturi's introspection is studied using a theoretical viewpoint called Pengkaedahan Melayu [Malay Methodology], introduced by Hashim Awang. Malay Methodology also discusses an approach known as pendekatan seni (arts approach). This approach is deemed suitable for examining the strengths of Zaen Kasturi's art as evident through the diction and metaphorical expression in his work. Zaen Kasturi's careful selection of words in crafting his poems creates an aesthetic effect and a "colouring of language" that clearly identifies Zaen Kasturias an accomplished poet. The high quality and style of Zaen Kasturi's metaphorical language and his ingenuity in creating new expressions and fresh, original idioms are unique attractions to draw attention to the issue of introspection. Diction and metaphor are not merely stylistic ornamentation but are intended to strengthen the link between vocabulary and implicit meaning. This group of poems does not disregard the importance of art in the sharing of meaning, especially of content with introspective value.
\end{abstract}

Keywords: Malay methodology, arts approach, Zaen Kasturi, poem, diction, metaphor, implicit meaning

\title{
PENDAHULUAN
}

Dalam penghasilan sesebuah puisi, ia didasari oleh pelbagai gaya bahasa untuk menjadikannya utuh dari aspek diksi, makna dan perlambangan. Puisi juga merupakan nukleus imaginasi penyair yang diterjemahkan dalam kata-kata. Maka, ia memerlukan keterlibatan idea dan ilham penyair untuk 
mengukuhkan puisi. Octavio Paz (1992, p. 30), dalam bukunya berjudul The Other of Voice, penyair Amerika Latin ini menyebut bahawa puisi ialah suara asli kemanusiaan. Kemanusiaan harus dilontarkan untuk menyampaikan pesan untuk masyarakat, dan sesuatu pesanan harus dihadirkan dalam bentuk yang variasi untuk mencapai audiens. Demikian sifat puisi mesti ditonjolkan melalui gaya bahasanya, atau dikenali juga sebagai majas. Gaya bahasa menurut Keris Mas bermaksud cara atau ragam bahasa itu dipakai, khususnya dalam tulisan dan karangan (1988, p. 31). Ragam bahasa memerlukan serapan nilai estetik untuk menimbulkan keseimbangan pola puisi dari beberapa aspek yang signifikan dalam proses penulisan misalnya diksi (pemilihan kata) dan metafora.

Penerapan gaya bahasa juga bergerak sebagai perangsang penghayatan puisi dengan lebih tekun dan menyeluruh. Menurut pandangan Robert Frost (dalam Kennedy, 1983, p. 393), Frost menegaskan bahawa "poetry is a rhythmical composition of words expressing an attitude designed to surprise and delight, and to arouse an emotional response". Frost berpendirian bahawa puisi ialah komposisi kata-kata yang beritma untuk memperlihatkan sikap yang bertujuan memberi suatu kejutan dan rasa senang dan merangsang tindak balas secara emosi. Dalam penciptaan puisi, penyair lazimnya menggembleng gugusan kata-kata, perasaan dan tuaian ilham, selanjutnya menyatukan ketiga-tiga ini untuk melahirkan sentimen kepada khalayak. Menurut kesepakatan Zuniar Kamaluddin Mabruri dan Sri Dewi Ratnasri (2015, p. 137) terhadap cerapan perasaan dalam puisi:

\begin{abstract}
Puisi mengungkapkan perasaan yang beraneka ragam. Tema puisi yang sama yang dilukiskan dengan perasaan yang berbeda akan menghasilkan puisi yang berbeda pula. Perasaan tersebut mampu merepresentasikan nada dalam puisi. Nada puisi adalah sikap batin penyair yang hendak diekspresikannya kepada pembaca. Nada puisi ikut mewarnai corak puisi itu, serta keadaan batin pembaca akibat membaca puisi disebut dengan suasana.
\end{abstract}

Pandangan tersebut memperlihatkan peranan perasaan dalam sesebuah puisi itu bertujuan menterjemahkan nada-nada penyair yang tidak semestinya dizahirkan secara konkrit atau perbuatan yang boleh dicapai indera manusia. Maka, wujud kewaspadaan penyair dalam menjalinkan idea dengan keterkaitan yang munasabah demi kelancaran dan tekal dalam tulisan mereka.

Dalam 77 Tuju: Siri Ingatan kepada Kawan (2015), himpunan puisi yang ditukangi Zaen Kasturi ketara menonjolkan kesendengan 
terhadap pemerihalan diksi yang khas. Hal ini demikian kerana penyair tidak sewenang-wenangnya memasukkan sesuatu yang bukan acuannya. Perapian idea dan pemilihan kata yang berlandaskan mesej yang hendak diamanahkan kepada khalayak ditunjukkan secara konotatif dan denotatif. Penggunaan Pendekatan Seni dalam Pengkaedahan Melayu diguna pakai bagi memperkukuh perbincangan. Menurut Hashim Awang (1998, p. 7) keindahan itu adalah berteraskan tauhid, maka keindahan yang didefinisikan itu selaras dengan unsur introspeksi dalam kumpulan puisi ini, iaitu proses muhasabah dan pencerminan diri. Aspek unsur keindahan yang berakar dalam karya sastera menjadikan Pendekatan Seni ini sebagai satu ukur penilaiannya. Lagi menurut Hashim Awang (2002), keindahan dalam sastera merujuk kepada keindahan meletakkan dirinya kepada nilai-nilai estetika Islamik dan tidak berselisihan dengan akidah serta ajaran agama.

Menyitir Mohd Ali Hashimi dalam bukunya, Keperibadian Muslim (1996, p. 30); peribadi seseorang Muslim yang utamanya adalah terhadap Tuhannya, iaitu seperti ditegaskan Hashim Awang sebagai "tauhid" dan Muslim terhadap dirinya atau yang disebut sebagai "rutin refleksi jiwa." Selain itu, Pendekatan Seni turut digarap daripada pandangan ini yang memperkatakan bahawa, "pembentukannya (sastera) dalam acuan yang ada keteraturan dan keindahan, terutama keindahan yang memiliki nilai-nilai makna dan hikmah, seperti yang terdapat pada keindahan alam semesta ciptaan Allah." (Hashim Awang,1994, p. 10). Rangkaian diksi yang diperoleh daripada telaah terhadap himpunan puisi 77 Tuju: Siri Ingatan kepada Kawan ini diberi penelitian yang terdapat dalam perbincangan seterusnya.

\section{KUMPULAN PUISI 77 TUJU: SIRI INGATAN KEPADA KAWAN}

Zaen Kasturi atau nama sebenar Zainal Palit, seorang penulis yang menguasai dua genre, iaitu cerpen dan puisi. Kumpulan puisi beliau, iaitu Katarsis (1993), kemudian pula terlahir Iga (2005), 77 Tuju: Siri Ingatan kepada Kawan (2014) dan Fajar Lingkung Lembayung (2020). Meski kekuatannya ialah puisi namun hasil karya prosa seperti cerpen juga terserlah menerusi lima buah kumpulan cerpen, Yuda (1992), Idola (1997), Rapsodi (1998), Taman Uzlah (2005) dan Zamindar (2017).

Kumpulan puisi 77 Tuju: Siri Ingatan kepada Kawan (2015) terbitan Institut Terjemahan \& Buku Malaysia, nukilan Zaen Kasturi dilihat sebagai teks kajian yang agak terkini dalam perkembangan genre puisi Melayu. 
Kumpulan ini memenangi kategori A: Kumpulan Puisi Hadiah Sastera Perdana Malaysia (HSPM) 2015/2016. Kumpulan puisi 77 Tuju: Siri Ingatan kepada Kawan dengan 77 buah puisi, turut diakui penyairnya sendiri sebagai puisi yang mengangkat tema persahabatan dalam pelbagai tafsiran. Sementara panel HSPM 2015/2016 mengungkap kumpulan ini,

... membawa tema kehidupan manusia yang mengejar impian dan cita-citanya yang tidak dapat melarikan dirinya daripada dogma, nilai tradisi, terumbang-ambing antara sikap pasif dengan cita-cita yang berkobar-kobar, tetapi kadangkala terbentur kepada cabaran dan dugaan.

\section{DIKSI}

Sasterawan Negara, Keris Mas (1988, p. 31) menyatakan bahawa bahasa wujud kerana kata, tiada kata, maka tiadalah bahasa. Demikian abjad, aksara, huruf dan kata mewakili proses penciptaan bahasa yang bersifat komunikatif, yakni suatu jalinan wacana yang menghubungkan bicara waima dalam bentuk lisan mahupun tulisan. Diksi merupakan pemilihan kata yang berindukkan erti dan makna yang mahu disampaikan. Menurut Keris Mas lagi, tiap kosa kata atau perbendaharaan kata dalam bahasa Melayu mengandungi erti dan makna. Keraf (1988, p. 24) merumuskan bahawa tiga perkara berkenaan diksi. Yang berikut, tiga perkara yang dikemukakan oleh Keraf:

"Pertama, pilihan kata atau diksi mencakup pengertian kata-kata
mana yang dipakai untuk menyampaikan suatu gagasan, bagaimana
membentuk pengelompokan kata-kata yang tepat atau menggunakan
ungkapan-ungkapan yang tepat dan gaya mana yang paling baik
digunakan dalam suatu situasi. Kedua, diksi adalah kemampuan
membedakan secara tepat nuansa-nuansa makna dari gagasan yang
ingin disampaikan, dan kemampuan untuk menemukan bentuk yang
sesuai (cocok) dengan situasi dan nilai rasa yang dimiliki kelompok
masyarakat pendengar. Ketiga, pilihan kata yang tepat dan sesuai
hanya dimungkinkan oleh penguasaan sejumlah besar kosa kata
terhadap bahasa tertentu."

Penguasaan kosa kata yang banyak oleh pengarang akan melahirkan tingkat makna yang berlapis-lapis. Perbendaharaan kata yang kaya mendorong penyair untuk mengolah diksi agar terbentuk sebuah komposisi bahasa yang 
sarat pengertian. Keakraban hubungan diksi dan kosa kata tidak dilonggarkan kerana kedua-duanya saling terkait, malah saling melengkapi.

Dalam kajian diksi pada himpunan puisi Zaen Kasturi dalam 77 Tuju: Siri Ingatan kepada Kawan, diksi yang dikaji terbatas pada kata-kata berbentuk konotatif. Puisi-puisi berkenaan dicorakkan dengan sifat evaluatif, iaitu taksiran nilai. Diksi yang dianalisis menggunakan kerangka Pendekatan Seni, iaitu cabang daripada teori Pengkaedahan Melayu. Hasil diksi memperlihatkan motif puisi yang introspektif, seperti yang dibincangkan sebelumnya.77 Tuju: Siri Ingatan kepada Kawan mewakili sisi Zaen Kasturi yang begitu inkuiri, santun dan sederhana dalam mewarnakan karyanya. Latar puisi yang tiada limitasi, berwajah sureal dan tujuan yang bergerak seperti labirin (maze) untuk menemukan jalan keluar (exit).

Menerusi puisi Zaen Kasturi, terdapat kecenderungan penyair mencetuskan pertanyaan yang memperlihatkan introspeksi, retrospeksi dan himpunan kemungkinan. Penegasan Zaen Kasturi berkenaan "ingatan" sebagai amanat untuk diamanahkan kepada "kawan" yang membawa maksud lebih daripada yang lazim diertikan. Zaen Kasturi turut melakukan pengulangan judul puisi, iaitu "ingatan kepada kawan i" sehingga "ingatan kepada kawan lxxxvii" sebagai tanda penekanan terhadap kepentingan makna "ingatan". Keberanian Zaen Kasturi mengungkapkan persoalan yang bersifat rohaniah melahirkan penerokaan metafizika juga. Penerokaannya tidak terbatas kepada ruang persahabatan yakni istilah "kawan" yang menjadi induk puisi tetapi Zaen Kasturi turut bergerak sebagai pemikir memasuki rongga kehidupan yang berat dengan warna agama, falsafah dan nilai kemanusiaan.

Analisis diksi ini berpandukan Pendekatan Seni yang digagaskan Hashim Awang berlandaskan jalan seni yang menuntun ke arah kerohanian dan keagamaan namun sedikit longgar dengan memberikan kebebasan dalam membongkar gali estetik puisi Zaen Kasturi ini. Walau bagaimanapun, Pendekatan Seni ini dimanfaatkan untuk melihat pemeragaan estetika menerusi capaian diksi dan perlambangan yang diperoleh dalam puisi berkenaan. Seni yang dibawa masih bertujuan memaparkan keindahan yang dianugerahkan oleh Allah SWT dalam membentuk ilham. Keseluruhan 77 judul puisi tidak dibincangkan namun beberapa judul puisi yang mengikut acuan seni, dibentangkan sebagai sasaran analisis.

Puisi "ingatan kepada kawan ix" begitu sarat dengan bahasa yang prismatis. Evi Karmila dan Yulsafli menjelaskan bahasa prismatis merujuk kepada "penyair memilih kata-kata yang menyebabkan pembaca berfikir 
terlebih dahulu untuk memahami maknanya. Makna kata yang digunakan kebanyakan makna kias" (2017, p. 83). Yang berikut dikemukakan permulaan puisi ini:

"malammu dan malamku tak sama gelitanya," katamu.

"namun bulanku dan bulanmu tak berkurang cahaya," kataku.

(hanya sesekali bintang di langitmu, bintang di langitku mencuba menyihir kita, mengajak kita berlumba berebut cahaya, kata kita).

(Zaen Kasturi, 2015, p. 12)

Bait ketiga berbunyi, "hanya sesekali bintang di langitmu, bintang di langitku mencuba menyihir kita, mengajak kita berlumba berebut cahaya, kata kita" dan memperlihatkan unsur introspeksi secara kias dan bersirat. Perkataan "bintang" lazimnya membawa pengertian berkenaan istilah sains, iaitu bebola jisim gas dan kedudukannya tinggi di angkasa. Namun begitu, dalam puisi ini, kosa kata "bintang" dipilih kerana "bintang" secara azali, sering berhubungan dengan "cahaya", seperti yang dinyatakan oleh penyair dalam frasa ini. Dalam puisi ini, "bintang" tidak lagi merujuk kepada pengertian yang biasa difahami tetapi merujuk pada makna konotatif, iaitu suatu petunjuk. "Cahaya" yang dimaksudkan dalam frasa ini pula membawa makna konotatif yang berkaitan keagamaan, iaitu Tuhan. Dalam Islam, Tuhan memberikan Nur (cahaya) yang menuntun manusia. Dalam puisi ini juga Zaen Kasturi memperlihatkan kejadian alam sebagai estetika yang luar biasa dan tanda kebesaran Tuhan. Keindahan alam seperti kejadian malam, bintang dan cahaya mengheret manusia untuk bertanya dan renungi. Demikian hal ini sepadan Hashim Awang (1995, p. 30) melalui gagasan Pendekatan Seni, iaitu nilai keindahan dan kemaknaan dalam setiap karya khususnya kesusasteraan yang berunsur Islam akan memancarkan keistimewaan dan ketinggian serta keagungan Allah.

Setiap manusia khususnya Muslim harus menjadi Mukmin yang sedar menurut Mohd Ali Hashimi (1996, p. 45), iaitu sering menimbulkan rasa jiwa muraqabah. Penyair menjalinkan untaian makna dengan mencerap unsur alam sebagai perlambangan. Hal ini bertepatan dengan ayat al-Quran:

\footnotetext{
"Sesungguhnya di dalam penciptaan langit dan bumi dan silih bergantinya malam dan siang terhadap tanda-tanda bagi orang-orang yang berakal."
}

(Surah Ali Imran 3:190) 
Begitu juga dengan bait lain dalam puisi ini memperlihatkan introspeksi dengan lapisan bahasa yang tebal dan tidak boleh difahami secara permukaan sahaja. Bait terakhir puisi "ingatan kepada kawan ix", iaitu:

(hanya sesekali belati di jiwaku, belati di jiwamu

Tak betah bertemu sesama kilaunya)

(Zaen Kasturi, 2015, p. 12)

Perkataan "belati" secara harfiahnya bermaksud sejenis senjata tajam untuk menikam. Namun begitu, penyair menyisipkan makna konotatifnya yang menyoroti pengertian berkenaan kekuatan atau kecekalan seseorang. "Belati" yang memiliki sifat bahaya dan mencederakan, namun belati juga ditanggap sebagai bentuk perlindungan yang menjadikan seseorang itu selamat daripada diserang atau dapat membalas semula serangan. "Belati" juga secara fizikalnya berkilat kerana permukaannya yang reflektif. Frasa "sesama kilaunya" merujuk cerminan diri menerusi kekuatan yang dimiliki. "Kilau" boleh bermaksud sinar daripada pantulan kepada cermin. Hal ini demikian menjadikan keseluruhan frasa tersebut secara konotatifnya ialah kekuatan atau ketabahan dalam diri seseorang, justeru menimbulkan kesan introspeksi.

Puisi "ingatan kepada kawan xxxi” ditukang dengan ringkas dan tidak sarat kosa kata yang berat namun peranan beberapa pemilihan kata mengukuhkan tubuh puisi ini untuk bersifat kendiri tanpa dukungan perlambangan yang lewah. Sebagai tamsilan, diturunkan keseluruhan puisi tersebut:
Kautahu?
Kebiadaban memungkinkan apa saja
Hingga secangkir kopi pahit
Lebih mahal harganya daripada
Sekolam darah syuhada

(Zaen Kasturi, 2015, p. 37)

Frasa "kebiadaban memungkin apa saja hingga secangkir kopi pahit lebih mahal daripada sekolam darah syuhada" memperlihatkan makna konotatif yang Zaen Kasturi ajukan dalam puisi ini. Bahagian "secangkir kopi lebih mahal daripada sekolam darah syuhada" menampakkan sindiran penyair berkenaan harga kemanusiaan digantikan dengan materi. Hal ini 
demikian kerana "kopi pahit" yang ditegaskan oleh penyair lebih bernilai daripada pengorbanan pejuang-pejuang kebenaran (yakni merujuk kepada "sekolam darah syuhada"). Frasa "sekolam darah syuhada" pula merupakan gambaran para pejuang (syuhada) yang gugur dan "sekolam darah" memberi pengertian hasil pengorbanan yang menuntut nyawa.

Dalam puisi ini, penyair menggunakan frasa konotatif makna dengan susunan diksi yang indah untuk memperihalkan tuntutan perjuangan diri atau dikenali sebagai jihad dalam ajaran Islam. Perkara ini bersesuaian dengan garapan Pendekatan Seni yang berteraskan keindahan berlandaskan jalan tauhid. Bagi Muslim, salah satu cara mencapai tauhid adalah dengan melaksanakan jihad. Konsep jihad yang dimaksudkan tidak terbatas pada perjuangan yang membuka jalan peperangan sesama manusia tetapi perlawanan dalam jiwa seseorang. Meskipun dalam puisi ini menceritakan kebimbangan penyair terhadap keadaan dunia yang mengangkat materi lebih tinggi daripada kebenaran, namun penyair juga memasukkan unsur introspektif dengan kata kiasan yang menyindir sikap manusia yang tidak lagi mementingkan kemanusiaan.

Makna konotatif dalam puisi "ingatan kepada kawan xxxiv" ini memperkarakan hal masa silam atau melontarkan pertanyaan yang dikepung retrospeksi oleh penyair. Dalam puisi ini, penyair memperkatakan tentang beberapa objek sebagai selingan perlambangan, iaitu:

Lilin-lilin yang bernyala pada tahun-tahun sebelumnya

Telah terpadam semuanya

(Zaen Kasturi, 2015, p. 40)

Pemilihan perkataan "lilin-lilin" secara harfiahnya merujuk objek yang menjadi sumber untuk menerangi sesuatu yang terdiri daripada sumbu. Namun begitu, dalam puisi berkenaan, "lilin-lilin" yang dimaksudkan penyair ialah bilangan usia. Demikian "lilin" secara lazimnya diasosiasikan dengan sambutan ulang tahun kelahiran seseorang. "Lilin-lilin" tersebut menjadi perlambangan secara retrospektif, iaitu imbau balik terhadap masa silam. Salah satu rukun introspeksi ialah kembali ke masa silam untuk menghitung amalan diri. Maka, frasa keseluruhan berikut menceritakan bilangan usia pada masa silam tidak akan kekal abadi untuk diingati.

Kemudian, makna konotatif yang lain terdapat dalam puisi yang sama, memperihalkan berkenaan hari ulang tahun seseorang. 
Kerana hari ulang tahun adalah mata rantai

Yang mengikat kukuh

Antara rantai kenangan di belakang

Dengan rantai kehidupan di hadapan

(Zaen Kasturi, 2015 p. 40)

Penyair menggunakan frasa "mata rantai" untuk merujuk ikatan perhubungan. "Rantai" bersifat mengikat atau mengunci sesuatu, manakala "mata" pula selain mewakili bahagian wajah, juga merujuk bahagian yang tajam pada sesuatu alat. Frasa ini memperlihatkan maksud cengkaman ikatan dalam sesebuah perhubungan. Dalam puisi berkenaan, penyair menggunakan perlambangan "rantai" sebagai tali pengikat yang mengukuhkan hubungan kenangan dan kehidupan, seperti yang dinyatakan pada dua baris terakhir; "antara rantai kenangan di belakang, dengan rantai kehidupan di hadapan".

Kad dan cenderamata telah terbungkus oleh kata

Hidup pun telah memilih usia.

(dan tugasmu sekarang, mudah

Hanya tersenyum)

(Zaen Kasturi, 2015, p. 41)

Nilai introspeksi dihadirkan dalam rangkap akhir puisi ini dengan diksi konotatif yang menggunakan objek untuk melapisi makna. Baris "kad dan cenderamata telah terbungkus oleh kata, hidup pun telah memilih usia" membawa pengertian peningkatan usia seseorang tidak tertakluk pada materi, pemilihan perkataan "kad" dan "cenderamata" merupakan hadiah yang lazim diberikan untuk meraikan ulang tahun kelahiran, namun penyair menegaskan bahawa kata-kata lebih bermakna. Kemudian penyair berintrospeksi dengan menukang baris seterusnya, "hidup pun telah memilih usia" yang menyoroti pengertian berkenaan ketentuan hidup mendewasakan usia. Demikian introspeksi ini menuntut seseorang untuk redha dan tawakal, seperti baris akhir puisi ini, "dan tugasmu sekarang, mudah - hanya tersenyum". Penyair menggunakan diksi konotatif terhadap perkataan "senyum", iaitu ekspresi manusia yang menunjukkan kegembiraan. Namun begitu, penyair menegaskan makna konotatif "senyum" sebagai tanda keredhaan dan tawakal seseorang. Introspeksi tidak terbatas pada proses renungan diri secara reflektif tetapi turut meliputi tawakal. Pemilihan 
kata-kata yang bersesuaian seperti ini bertujuan untuk menonjolkan imej estetik yang ingin penyair terjemahkan.

Hal ini bertepatan dengan pendirian Barfield pula dalam Pradopo (2009, p. 54) menjelaskan bahawa, “... bila kata-kata dipilih dan disusun dengan cara yang sedemikian rupa hingga ertinya menimbulkan atau dimaksudkan untuk menimbulkan imaginasi estetik, maka hasilnya itu disebut diksi puitis. Kata-kata dalam puisi bersifat konotatif sehingga memiliki kemungkinan makna yang tidak tunggal." Penyair mempertaruhkan mainan imaginasi untuk mewakili perkataan hingga maknanya dapat dicapai oleh pembaca.

Beralih ke puisi "ingatan kepada kawan lv." Kandungan puisi ini sarat perlambangan makna konotatif yang memperihalkan introspeksi. Yang berikut petikan rangkap puisi tersebut:

Kataku:
Usia adalah cermin
Yang melantunkan wajah ke muka
Hingga pintu dan jendela pun sedemikian terbuka
Dikunjungi cahaya

(Zaen Kasturi, 2015, p. 62)

Penyair menyandingkan unsur introspeksi pada baris kedua, "usia adalah cermin" yang memperlihatkan konotatif "cermin". Pengertian "cermin" pada dasarnya ialah muka kaca yang digunakan untuk melihat bayang diri sendiri yang bertepatan dengan konsep introspeksi yang bertujuan untuk evaluasi diri dengan memantulkan peribadi. "Cermin" dijadikan konotatif refleksi keperibadian diri. Dalam puisi ini, baris "usia adalah cermin yang melantunkan wajah ke muka" diertikan oleh penyair bahawa perbilangan usia memantulkan hakikat diri. Fokus puisi ini ialah pemilihan kosa kata untuk memaknakan introspeksi. "Wajah" dan "muka" ialah dua perkataan yang sinonim tetapi penyair menggunakan konotatif berbeza untuk setiap satunya. Konotatif "wajah" lebih bersifat mujarad, manakala "muka" pula bersifat fizikal (boleh dicapai indera).

Perbezaan diksi ini diwujudkan kerana "wajah" cenderung mewakili keadaan jiwa (tidak konkrit), manakala "muka" dalam konteks puisi ini pula khusus merujuk sebahagian anggota badan (dari dahi ke dagu). Baris seterusnya "hingga pintu dan jendela pun sedemikian terbuka dikunjungi cahaya" lebih bersifat rohaniah. Penyair menggambarkan manusia ini ibarat rumah; mempunyai jendela dan pintu (merujuk pada mata, hati, 
jiwa) yang harus terbuka. Maka, frasa "dikunjungi cahaya" bermaksud penyair menyatakan keterbukaan jiwa akan membawa masuk hidayah. "Cahaya" selain pengertian Tuhan (Nur -Yang Maha Memberi Cahaya), ia juga bermaksud pencerahan (enlightenment) seperti wahyu atau hidayah. Keseluruhan rangkap puisi ini jelas menimbulkan aspek introspeksi melalui pemilihan diksi konotatif yang evaluatif.

Begitu introspeksi turut diangkat dalam puisi "ingatan kepada kawan lxii" menerusi diksi yang tertentu. Puisi ini diawali seperti fragmen rangkap seperti yang berikut:

Waktu tak berhasil membina tembok antara kita

Kerana batunya daripada longgokan debu

Yang dibawa angin - kian ke mari

Datang hujan, lenyaplah ia

Ia semata debu

Apa diharap pada debu

Yang mengapung antara suram kabut dan lesu matahari

Kemudian perlahan-lahan turun

Hinggap di hujung sepatu

Kalau debu itu tembok

Datanglah hujan, mohon...

(Zaen Kasturi, p. 68)

Dalam rangkap berkenaan, penyair menyatakan kegagalan waktu untuk menghalang dirinya. Penyair memaknakan "waktu" sebagai konotatif kepada "ketentuan". Baris tersebut menceritakan ketentuan tidak membataskan perjalanan mereka. "Tembok" pula menjadi konotatif kepada "halangan". Berlaku pengulangan kosa kata "debu". Secara literalnya, "debu" bermaksud habuk yang halus, lazimnya daripada tanah. "Debu" sering diertikan sebagai sesuatu yang tidak dipedulikan dan konotatifnya ditinjau bersifat negatif kerana dianggap juga sebagai kotoran. Frasa "apa yang diharap pada debu yang mengapung antara suram kabut dan lesu matahari" membuktikan status debu yang rendah dan hanya didapati dalam keadaan yang tidak bersih, seperti dimaknakan oleh Zaen Kasturi, iaitu "suram kabut" dan "lesu matahari". Kedudukan debu dianggap rendah dan tidak mulia seperti yang ditegaskan pada baris berikutnya, iaitu "kemudian perlahan-lahan turun hinggap di hujung sepatu". 
Selanjutnya, penyair menyatakan harapannya agar "debu" itu dibersihkan, menerusi baris "datanglah hujan, mohon". Konotatif yang dibawa penyair memperlihatkan perihal kedudukan manusia diibaratkan sebagai "debu" yang kerdil di sisi Allah SWT dan konotatif "hujan" pula merujuk kemaafan Allah SWT. Penyair mengetengahkan soal kehambaan dan introspeksi diri dengan ungkapan diksi yang puitis untuk memberikan kesan kepada pembaca. Ungkapan tersebut dibentuk sebagai susunan naratif yang memuatkan keindahan kata-kata yang dipilih oleh penyair. Sehubungan dengan itu, jalur diksi sepadan dengan Pendekatan Seni yang menyatakan keindahan dikenal pasti menerusi pelbagai aspek atau unsur pembinaannya, iaitu berbentuk harfiah dan dalaman, gaya penceritaan, kaedah pendedahan tema dan watak, pemakaian sudut pandangan dan gaya bahasanya (Hashim Awang, 1994 p.10).

Puisi ini pula menyingkap perihal masa silam antara penyair dan sahabatnya. Antara bait puisi yang menjelaskan jalan retrospeksi penyair:

kita sama-sama mencabut rumpun kenangan

dari belukar nasib yang telah lama kita tinggalkan

di sini

(Zaen Kasturi: 15)

Penggunaan metafora "rumpun kenangan" sebagai perlambangan kepada himpunan kenangan penyair dan sahabatnya. Pemilihan kosa kata "rumpun" sebagai acuan kepada keakraban hubungan persahabatan mereka kerana "rumpun" bererti tumbuhan yang berkelompok-kelompok dan berkongsi jenis yang sama. Maka ini menyingkap makna bahawa persahabatan mereka umpama rumpun kerana saling berkait. "Rumpun kenangan" merentangkan maksud bahawa masa silam begitu berhubung rapat dengan diri penyair.

Penyair turut memakai gandingan dua perkataan yang bersifat mujarab untuk melahirkan frasa yang tersirat dan memiliki makna konotatif, iaitu

Antara pohon kekabu dengan selang-seli

Rumpun lalang belakang rumah, kita membidik

Si anak belibis kala senja tak semerah nasib kita

Zaman kanak itu

(Zaen Kasturi, p. 15) 
Frasa "senja tak semerah nasib kita" dimasukkan penyair untuk memperlihatkan keadaan persahabatan mereka. Penyair menyerap unsur waktu, iaitu "senja". Menurut Zurinah Hassan (2010, p. 168), waktu senja merupakan peringatan terhadap kehidupan di dunia yang tidak abadi. Peri pentingnya unsur "senja" berlandaskan ayat al-Quran, iaitu Surah al-Asr:

"Demi masa. Sesungguhnya manusia itu dalam kerugian kecuali orang-orang yang beramal soleh, dan mereka pula berpesan-pesan dengan kebenaran serta berpesan-pesan dengan sabar."

Kemudian makna konotatif "senja" pula diikuti dengan "tak semerah nasib kita zaman kanak kita". Perlambangan warna memainkan peranan dalam mengekspresikan emosi penyair. "Merah" mewakili maksud keberanian. Penyair memperincikan bait "senja tak semerah nasib kita" yang memaparkan nasib persahabatan mereka yang tidak lagi ampuh seperti waktu mereka kanak-kanak yang diperkatakan, iaitu "zaman kanak kita". Penggunaan "senja" mewakili usia yang tua dan ketuaan mengajak penyair untuk melakukan perenungan.

Seterusnya, puisi “ingatan kepada kawan xi” menggunakan pendekatan introspeksi dalam dua pemilihan kosa kata yang berbeza untuk menampilkan unsur penilaian diri. Yang berikut merupakan petikan rangkap:

"nanti kita solat," kataku. "tapi bulu-bulu burung ini

Perlu kita kutip agar esok belukar ini akan

Seperti selalu: sunyi dan bersih," katamu.

(Zaen Kasturi, 2015, p. 15)

Penyair menggunakan perkataan "solat" sebagai diksi konotatif yang menggambarkan rutin introspeksi. "Solat" ialah ibadah yang wajib dilaksanakan oleh setiap Muslim. Konotatif "solat" yang ditegaskan oleh Zaen Kasturi cenderung memperlihatkan konsep penghayatan solat secara total. Hal ini demikian kerana solat merupakan penyucian jiwa. Rukun muhasabah pula melibatkan penyucian dan pemurnian jiwa. Maka, diksi "solat" menjadi tanda introspeksi. Kepentingan solat sebagai urusan introspeksi diperkatakan oleh Nik Siti Khadijah, Hasanah (2016, p. 128). Yang berikut merupakan pandangan yang diketengahkan berkenaan dengan hubung kait solat dan introspeksi: 
"Penyucian jiwa melalui pendekatan muhasabah dalam penghayatan shalat amat berkait rapat dalam menggalakkan lahirnya seseorang Muslim yang dapat membersihkan dirinya daripada sifat-sifat buruk dan keji. Kaedah penyucian jiwa melalui pendekatan muhasabah dalam penghayatan shalat adalah disiplin ilmu tasawuf yang berkait rapat dengan akhlak seseorang Muslim. Dalam penyucian jiwa ini, seseorang Muslim mestilah berusaha membina kekuatan rohani yang bermatlamatkan makrifah kepada Allah SWT."

Menerusi pandangan mereka, solat merupakan pendekatan muhasabah untuk membersihkan dirinya yakni menyucikan rohaniah kerana solat juga meliputi aspek akhlak Muslim. Solat harus ditunaikan dengan bertujuan untuk meraih redha dan pencerminan peribadi. Peranan solat mengingatkan manusia bahawa kedudukan mereka sebagai abdun (hamba) yang melakukan pengabdian kepada Allah SWT. Yang berikut ialah pendapat digagaskan oleh Hairi (2016), iaitu:

"Lebih tegas lagi Allah SWT menyatakan bahawa tujuan penciptaan manusia untuk mengabdi kepada-Nya. Namun ketaatan, pengabdian dan ibadah yang dilakukan adalah untuk kepentingan manusia itu sendiri. Karena dengan ibadah itu manusia akan memahami dan menyadari eksistensi dirinya sebagai makhluk."

Kedua-dua pandangan yang dikemukakan oleh kesepakatan Nik Siti Khadijah, Hasanah dan Hairi merungkaikan perihal muhasabah melalui ajaran Islam. Maka, menerusi pendapat begini, terdapat keterkaitan perkataan "solat" sebagai diksi konotatif dan unsur introspeksi. Di sini, penyair meletakkan perkataan "solat" sebagai konotatif yang tidak sekadar bererti ibadah wajib tetapi selaras dengan makna introspeksi. Kemudian, dalam puisi yang sama, pemilihan "sunyi" sebagai diksi konotatif yang mewakili introspeksi. "Sunyi" bermaksud suasana yang tidak kedengaran sebarang bunyi (suara). Namun begitu, dalam puisi ini, penyair menggambarkan "sunyi" sebagai alternatif kepada keseorangan atau kesendirian seseorang. Demikian "sunyi" sinonim dengan urusan muhasabah. M. Hariyanto (2016) menegaskan dalam Islam, salah satu bentuk evaluasi diri yang digalakkan adalah ketika seseorang itu berada dalam keadaan bersendirian kerana penghayatan lebih menyeluruh dan dapat menghitung semula amalan. Penegasan beliau berlandaskan dua 
pendapat Umar Al-Khathab yang terkandung dalam hadis Mauquf, Riwayat At-Tirmidzi, Sunan at-Tirmidzi, iaitu:

\begin{abstract}
"Koreksilah diri kalian sebelum kalian dihisab dan berhiaslah (dengan amal shalih) untuk pagelaran agung (pada hari kiamat kelak)" dan pendapat kedua pula "Hamba tidak dikatakan bertakwa hingga dia mengevaluasi dirinya sebagaimana dia mengevaluasi temannya dari mana (dirinya) memeroleh makanan dan pakaiannya."
\end{abstract}

Maka, pandangan yang berikut mendukung makna yang disampaikan oleh penyair dalam puisi ini. Introspeksi yang dianjurkan oleh Islam mementingkan pengabdian jiwa secara total dan demi melaksanakan penyucian jiwa.

\title{
METAFORA
}

Dalam proses penciptaan puisi, penggunaan metafora sangat signifikan. Kebanyakan penyair membentuk metafora untuk menggembleng makna yang baharu. LE Luanmas memetik pandangan Banhart (1973:1294) berkenaan metafora, iaitu:

Metafora merupakan salah satu gaya bahasa perbandingan yang biasanya ditemui dalam kehidupan sehari-hari, baik secara lisan maupun tulisan. Metafora berasal dari bahasa yunani yang merupakan gabungan dari dua kata yaitu meta artinya pindahan dan Pherein yang artinya membawa. Secara keseluruhan metafora berarti pindahan / transfer.

Metafora terdiri dengan gabungan dua perkataan yang berbeza untuk menghasilkan satu makna berlainan. Seperti pendapat Banhart bahawa metafora ditinjau sebagai pindahan makna. Kemudian, menurut Keris Mas (1988) pula, beliau berpendapat bahawa metafora ialah:

...gaya kiasan atau bandingan yang tidak lain daripada perumpamaan. Tetapi metafora tidak terikat lagi kepada makna dua lapis dan tidak pula memerlukan pengutaraan perkara yang dijadikan bandingan. Maka pada hakikatnya metafora itu dapat dikatakan ungkapan atau simpulan bahasa bermakna bandingan atau analogi. Dan seperti ungkapan atau simpulan bahasa, metafora dapat berdiri sendiri 
sebagai unit sendiri mengambil tempat dan fungsi sendiri dalam struktur sintaksis.

Menerusi pendapat Keris Mas berikut, metafora bersamaan dengan analogi yang bererti perumpamaan. Namun, metafora ini bersifat kendiri. Makna yang diajukan tidak perlu didukungi perumpamaan lagi kerana ia mampu berdiri sendiri.

Kajian metafora dalam himpunan puisi Zaen Kasturi dalam 77 Tuju: Siri Ingatan kepada Kawan, bertujuan merungkai lapisan introspeksi yang diajukan oleh penyair melalui penulisan puisi-puisi bermotifkan sarat kiasan. Metafora yang dianalisis diperlihatkan menerusi lorong Pendekatan Seni, iaitu cabang daripada Pengkaedahan Keagamaan. Hasil analisis menampakkan sifat puisi yang introspektif sebagai mauduk kajian. Analisis metafora menerusi Pendekatan Seni bertautan dengan nilai seni atau estetik berlandaskan ajaran Islam. Metafora yang didapati berhubungan dengan keindahan yang dianjurkan dalam Islam yang terdiri daripada rampaian muhasabah. Menurut panel HSPM 2015/2016 lagi,

Membaca kumpulan 77 Tuju ini kita merasakan kepenyairan Zaen Kasturi yang sudah memasuki dunia kematangan. Puisinya kaya dengan metafora yang hidup dan segar, personifikasi yang baru, tautan yang koheren, dan juga falsafah yang [penuh dengan tenaga hidup baru dan ingatan kepada kekuasaan Ilahi. Dia juga hadir dengan kreasi kata-kata baharu dan tidak kurang juga mengembalikan diksidiksi archivistik yang masih boleh digunakan seperti mengewangi, merinding, si luman, lepu dan lain-lain.

Dalam puisi "ingatan kepada kawan xxii” memperlihatkan gaya bahasa penyair yang teliti dan pemakaian perlambangan yang sarat pengaruh alam. Unsur alam bertujuan sebagai latar perenungan penyair. Yang berikut sebahagian puisi tersebut:

Serangga di sekitar kita bertolakan, berebut madu usia

Di kelopak nama yang satu demi satu luruh

Daripada kembang waktu yang menguncup dalam diam

Tak pernah kauhiraukan. Lalu katamu:

"Serangga tetap serangga - sering kali dimainkan

Angin dan suasana, hingga padang tempat 
Kita berlari dahulu tak lebih masa silam yang dikarati Hujan kenangan."

(Zaen Kasturi, 2015, p. 27)

Frasa "madu usia" berbentuk metafora, iaitu gandingan hal konkrit (yang boleh dicapai pancaindera), iaitu "madu", manakala "usia" pula bersifat mujarad. Definisi "madu" bererti cecair manis yang terdapat di dalam sarang lebah, namun madu turut bermaksud sesuatu yang manis (yang tidak konkrit), manakala usia pula merujuk hayat atau nyawa. Gandingan madu usia ialah perumpamaan kepada kemanisan dalam kehidupan, iaitu kesenangan atau kegembiraan. Klausa "serangga di sekitar kita bertolakan, berebut madu usia" yang berbentuk metaforis kepada perenungan penyair terhadap kehidupan yang dialaminya, iaitu saat-saat kegembiraan. Seperti telah dibincangkan sebelum ini, perenungan ialah salah satu rukun berintrospeksi. Penyair juga meletakkan perenungan menerusi metafora "hujan kenangan." Perkataan hujan bererti fenomena cuaca. Hujan sering diasosiasikan dengan kesedihan dan halangan. Hal ini didukungi dengan pandangan Zurinah Hassan (2010, p. 131), iaitu:

Perkara ini terjadi kerana hujan menyekat perjalanan atau aktiviti. Di dalam hujan terpaksa menghentikan aktiviti dan mengurung diri di dalam rumah. Sekali lagi, di dalam keadaan tidak bekerja mula mengenang sesuatu yang mungkin dapat di lupakan semasa bekerja. Keadaan semakin samar dan kabur dan dikaitkan dengan rasa tidak menentu. Hujan yang menitis juga menyerupai air mata yang mengalir.

Ia berhubungan dengan perkataan yang digandingkan, iaitu "kenangan" yang bermaksud "ingatan." Maka, metafora "hujan kenangan" bermaksud ingatan kepada perkara silam yang mendukakan. Terkait dengan aspek introspeksi, penyair berevaluasi dengan mengingati perihal lampau.

Perkara yang mirip didapati pada rangkap seterusnya. Baris yang memperlihatkan klausa metaforis adalah seperti yang berikut:

Kataku: "serangga tetap serangga - sering kali

Berawas pada angin dan suasana, hingga padang

Tempat kita berlari dahulu tak ubah masa kini yang

Dikilati gerimis impian.”

(Zaen Kasturi, 2015, p. 27) 
Imej metafora ketara ditonjolkan menerusi bait akhir baris keempat, iaitu "dikilati gerimis impian." "Gerimis" yang sinonim dengan maksud hujan yang dijelaskan sebelumnya, dan diikuti dengan "impian" yang bererti cita-cita. Frasa "gerimis impian" boleh diertikan cita-cita yang banyak. Namun begitu, konteks puisi ini, frasa tersebut bermaksud keinginan yang tidak dapat dimanfaatkan. Penggunaan majas metafora sedemikian bertujuan menterjemahkan imaginasi dengan efektif untuk difahami pembaca. Hal ini selaras dengan Yudi Martono (2013, p. 812) berpandangan metafora itu adalah:

... kata-kata yang bermajas metafora penyair menggunakan kata-kata yang begitu dekat dengan pembaca. Kedekatan kata-kata dengan pembaca ini, pembaca bisa menginterprestasikan makna kata-kata yang terdapat dalam puisi tersebut. Sehingga puisi tersebut memiliki tingkat keterbacaan yang tinggi. Tingginya tingkat keterbacaan dalam puisi akan sebanding lurus dengan tingkat pemahaman pembaca. Sehingga makna kata tersebut bisa dipahami dengan baik oleh pembaca.

Penciptaan metafora oleh kebanyakan penyair berlandaskan keinginan untuk mendekatkan hubungan penyair dan pembaca tanpa merasa imaginasi terbatas kerana gaya bahasa yang sukar diinterpretasi. Maka, gaya bahasa metafora memudahkan urusan komunikasi antara penyair dengan pembaca lalu menawarkan makna yang selaras dengan tahap pemahaman pembaca. Hubungan metafora ini merangkumi pemahaman Hashim Awang terhadap kerangka Pendekatan Seninya.

Metafora didapati juga dalam puisi berjudul "ingatan kepada kawan xxv."Dua baris yang menonjolkan majas metafora menerusi unsur alam sebagai cerapan imej.

Katamu: "kita menuju pulau impian"

Kataku: "kita menuju daratan kenyataan."

(Zaen Kasturi, 2015, p. 31)

Metafora "pulau impian" dipecahkan kepada dua perkataan yang terdiri daripada bersifat konkrit dan mujarad. Pengertian "pulau" yang lazim difahami ialah tanah atau daratan yang dikelilingi air. "Pulau" juga disifatkan sebagai tempat yang terasing kerana hanya didapati di kawasan laut, dan kebiasaannya kedudukan pulau jauh daripada darat. "Impian" ialah cita-cita. 
Maka, "pulau impian" ialah gandingan untuk menimbulkan imej metafora yang bermaksud syurga atau utopia, iaitu tempat yang menyenangkan dan bebas daripada keburukan.

Namun begitu, konteks "pulau impian" ini lebih cenderung ditinjau sebagai angan-angan. Penyair mengekspresikan kemahuan sahabatnya sebagai manusia untuk menuju syurga tetapi penyair menyanggah keinginan tersebut menerusi baris kedua, iaitu "kataku: kita menuju daratan kenyataan." Frasa metafora "daratan kenyataan" menggambarkan realiti. Hal ini demikian kerana "darat" ialah kawasan tanah, namun daratan juga mempunyai maksud "menurun." Perkataan "kenyataan" ialah sinonim kepada realiti. Gabungan "daratan kenyataan" yang diajukan oleh penyair membawa pengertian bahawa manusia harus kerap menyedari keberadaan diri, iaitu tetap berada di darat dan meladeni kenyataan dalam hidup.

Penggunaan metafora tersebut memperlihatkan keupayaan Zaen Kasturi sebagai penyair dalam penzahiran makna yang introspektif melalui ungkapan metafora tersendiri. Dalam puisi ini, Zaen Kasturi menjelaskan proses introspeksi ini berlaku setelah manusia menyedari keadaan diri dan muraqabah menerusi susunan majas metafora untuk menimbulkan kesan terhadap pembaca. Hal ini bersesuaian dengan Pendekatan Seni yang menegaskan kepentingan gaya bahasa indah seperti aspek metafora, malah Hashim Awang (1994, p. 13) menyatakan seni (Islam) memberikan keutamaan kepada pemikiran dan makna itu diberi bentuk sehabis indah dan unik melalui stylization (penggayaan bahasa). Penggayaan bahasa dalam Pendekatan Seni menurut Hashim Awang akan menunjukkan aspek keindahan bahasa, iaitu keindahan luaran boleh dilihat daripada bentuk visual dan penggunaan gaya bahasa manakala keindahan dalaman merujuk aspek falsafah pemikiran dan mesej yang dibawa dalam sesuatu karya. Hal ini penyair sorotkan untuk membawa pembaca menyelami nilai-nilai estetika Islam berteraskan ketakwaan kepada Allah SWT.

Puisi seterusnya ialah puisi "ingatan kepada kawan iii”. Beberapa metafora dimasukkan oleh penyair untuk merungkai introspeksi. Yang berikut merupakan sebahagian metafora yang didapati dalam puisi berkenaan:

Dengan apa dapat kautumpulkan tajam mata takdir Sedang kau tak lebih hanya debu-debu masa

(Zaen Kasturi, 2015, p. 3) 
"Mata" membawa dua pengertian, iaitu alat pancaindera pada muka manusia untuk melihat, dan kedua ialah bahagian tajam pada sesuatu alat. Sedangkan "takdir" pula sesuatu yang ditentukan Allah SWT terlebih dahulu. Kedua-dua perkataan tersebut digandingkan dan membentuk metafora "mata takdir" yang dianalogikan sebagai cengkaman takdir. Perumpamaan tersebut jelas tergambar pada bait "dengan apa dapat kautumpulkan tajam mata takdir" yang ketara mengibaratkan tindakan manusia untuk melawan kehendak takdir. Kemudian ia diikuti dengan baris metaforis "sedang kau tak lebih hanya debu-debu masa." Perkataan "debu" merujuk habuk halus namun secara konotatifnya memperlihatkan seseorang yang berdarjat rendah, iaitu hamba, manakala "masa" pula sinonim dengan perkataan waktu, tetapi dalam konteks lebih mendalam, masa juga mewakili jangka hayat manusia. Maka, metafora "debu-debu masa" menyifatkan kedudukan manusia yang kerdil di sisi Allah SWT. Perihal kekerdilan diri yang dianjurkan oleh Zaen Kasturi membawa kepada jalan muhasabah yang dituntut dalam Islam. Setiap Muslim harus berintrospeksi maka penyair menegaskannya menerusi keindahan ungkapan metafora untuk menyuntik rasa rendah diri dan kehambaan.

Hal ini bersesuaian dengan Pendekatan Seni, iaitu keindahan berteraskan tauhid. Hashim Awang (1998, p. 8) menegaskan bahawa penghasilan atau penulisan sastera juga merupakan suatu amalan yang turut dituntut. Keindahan yang terkandung nilai-nilai makna dan hikmah, seperti yang terdapat pada keindahan alam semesta ciptaan Allah SWT. Keindahan sedemikian melahirkan perenungan yang dalam untuk manusia menginsafi fahaman kehambaan diri yang merupakan antara tunjang jalan muhasabah. Sehubungan dengan hujah Hairi (2016), peranan manusia dalam agama Islam adalah sebagai abdun, iaitu hamba. Beliau mengemukakan pandangannya, iaitu:

"Penyair melontarkan pertanyaan tentang daya manusia yang ingin menentang arus takdir sebagai dijadikan introspeksi kerana baik dan buruk sesuatu takdir merupakan peluang untuk manusia bermuhasabah dan mengangkat musibah dan kehinaannya. Perkara ini ditinjau sebagai manfaat musahabah dalam ajaran Islam."

M Hariyanto (2016, p. 5) memperincikan hadis yang merakamkan nasihat Umar bin Al-Khathab radhiyallahu 'anhu dalam Hadis Riwayat at-Tirmidzi dari Syaddad bin Aus, Sunan at-Tirmidzi, iaitu: 
"Sesungguhnya hisab pada hari kiamat akan menjadi ringan hanya bagi orang yang selalu menghisab dirinya saat hidup di dunia."

Kemudian metafora seterusnya adalah seperti yang berikut:

Berkali-kali kau berteriak: "lepaskan aku daripada belenggu waktu."

(Zaen Kasturi, 2015, p. 3)

"Belenggu" secara harfiahnya membawa pengertian alat untuk mengikat kaki atau tangan (gari), namun belenggu turut dianggap sebagai sesuatu yang mengikat kebebasan, dalam erti kata lain "terikat." Waktu, seperti dibincangkan sebelumnya adalah jangka masa (tertentu). Metafora "belenggu waktu" dalam puisi ini merujuk keterikatan waktu kepada kehidupan manusia. Manusia terbatas dalam banyak perkara, salah satunya ialah waktu. Dalam bait ini, penyair menggambarkan hakikat manusia mendiami dalam ruang dan waktu. Keterikatan waktu yang dimaksudkan adalah untuk menunjukkan perbatasan manusia dalam kehidupan. Baris "lepaskan aku daripada belenggu waktu" ialah gambaran penyair yang mewakili lumrah manusia mahu merdeka daripada dikawal masa. Tetapi baris metaforis ini juga boleh dilihat dari sudut pandang yang introspektif dan separa mistik, iaitu mendorong kepada makna keinginan untuk melepaskan keterikatan jiwa dari dunia (waktu disinonimkan dengan ruang fizikal yang terbatas seperti dunia). Perihal ini berhubungan juga dengan pandangan Yusuf Qardhawi dalam Muhammad Abdul Jawad (2004, p. 35) yang menyatakan:

“... bahwa masa dan waktu adalah satu hal yang paling berharga dari emas dan perak dan dari segalanya. Ini disebabkan waktu adalah kehidupan (nyawa) manusia. Dengan berkurangnya/berjalannya waktu, maka berkurang jugalah umur manusia."

Puisi seterusnya berjudul "ingatan kepada kawan xxvi" yang menghidangkan metafora menggunakan unsur alam.

Ke mana akan terkelintar daun hayatmu

Ke denai-denai yang di kiri kanannya

Belukar sengketa

Atau ke lorong-lorong yang di depan dan di belakangnya

rimba ukhuwah? 
(Zaen Kasturi, 2015, p. 32)

Pengertian "daun" pada dasar harfiahnya ialah bahagian tumbuhtumbuhan yang keluar pada batang seperti dahan atau akar. Sedang "hayat" mengandungi maksud nyawa atau kehidupan. Penyair menyandingkan "daun" dan "hayat" membentuk satu metafora "daun hayat." Jika dikupas secara terperinci, demikian daun secara fizikal hanya tumbuh dengan ditumpangi ranting atau dahan, kemudian berkembang dan berhelai-helai. Daun turut diibaratkan sebagai tempat yang dinikmati oleh pelbagai pihak seperti unggas, serangga dan lain-lain. Maka daun ditinjau berkeadaan yang menyenangkan. Namun begitu, sifat daun juga akan kering dan gugur, yang membawa pengertian sirat kepada kematian. "Hayat" merupakan anugerah Allah SWT kepada manusia dan seluruh kejadian. Maka, "daun hayat" ialah metafora yang diangkat penyair untuk mengibaratkan kehidupan ini persis daun yang berhubungan dengan banyak perkara namun ia akan menemukan pengakhiran.

Metafora "belukar sengketa" pula menunjukkan perbalahan yang penuh cabaran. Demikian kerana "belukar; ialah kawasan tanah yang padat ditumbuhi pohon-pohon kecil, manakala "sengketa" bererti perkelahian yang disebabkan oleh pendapat yang berlainan. Metafora seterusnya pula "rimba ukhuwah" yang memperlihatkan makna kebesaran hubungan silaturahim. "Rimba" ialah hutan, iaitu kawasan yang tebal dengan tumbuh-tumbuhan dan lazimnya skala besar, manakala ukhuwah pula bermaksud persaudaraan. Dalam Islam, persaudaraan itu signifikan kerana saudara juga merangkumi sahabat, dan sahabat merupakan cerminan diri. Perkelahian dan persaudaraan barangkali berlawanan tetapi kedua-duanya mendorong kepada introspeksi. "Sengketa" di sini tidak diertikan dengan maksud yang lazim difahami tetapi lebih merujuk kepada perbalahan jiwa, iaitu melawan nafsi. Gandingan "belukar" bertujuan memberikan gambaran untuk selaras dengan tingkat pemahaman pembaca. Begitu ukhuwah merupakan tuntutan agama kerana persaudaraan mengukuhkan keperibadian seseorang. Kesemua metafora yang terdapat dalam puisi ini ditonjolkan oleh penyair sebagai refleksi dan introspeksi yang tinggi secara tersirat. Penggunaan perkataan yang tepat, menimbulkan makna secara imaginatif menerusi gabungan perkataan untuk mewujudkan suatu pengertian baharu.

\section{KESIMPULAN}

Hasil penelitian melalui garapan teori Pengkaedahan Melayu, khasnya 
Pendekatan Seni memperlihatkan bahawa dalam kumpulan puisi 77 Tuju: Siri Ingatan kepada Kawan yang ditukangi oleh Zaen Kasturi membawa diksi, iaitu diksi konotatif yang menyoroti pemilihan kosa kata yang tepat untuk mewakili makna tersirat berlandaskan gagasan teori ini, iaitu keindahan berteraskan tauhid. Dalam kajian ini, bentuk pengucapan puisi Zaen Kasturi berlandaskan nilai estetik yang tidak bercanggah dengan agama Islam bersesuaian dengan aplikasi Pendekatan Seni yang mengetengahkan aspek keindahan dalam karya sastera sebagai tunjang persoalan.

Sehubungan dengan itu juga aplikasi Pendekatan Seni menumpukan keindahan nilai-nilai estetik Islam yang tidak berselisihan dengan akidah Muslim dibuktikan menerusi tanggungjawab penyair menghubungkan pemahaman dan pengetahuan puisi agar tidak menimbulkan penyimpangan dan kekeliruan kepada pembaca. Kemudian, penelitian ini turut mendapati jejeran metafora digunakan dalam puisi-puisi tersebut selari dengan tuntutan aspek bentuk visual dan penggunaan gaya bahasa dalam Pendekatan Seni. Sisi ini menampilkan kedalaman karya melalui majas serta maknanya. Metafora digunakan oleh penyair banyak meminjam unsur alam untuk digandingkan bersama-sama nilai-nilai abstrak bagi membentuk makna yang baharu. Demikian keindahan merupakan tuntutan beragama, lebih-lebih lagi untuk mengangkat kebenaran. Penelitian ini menyerlahkan kepintaran Zaen Kasturi menggunakan gaya bahasa seperti diksi dan metafora untuk mengemukakan kesan keindahan bersama-sama kecenderungan rohaniah berteraskan ajaran Islam kepada pembaca agar melahirkan keimanan, ketakwaan dan kecintaan kepada Allah SWT.

\section{RUJUKAN}

Ahmad Khamal Abdullah, Rahman Shaari \& Lim Swee Tin. (2017). Laporan Hadiah Sastera Perdana Malaysia (HSPM) 2015/2016. Dewan Sastera, Mei, 9-15.

Banhart, Clarence. (1973). The World Book Dictionary. Chicago: Field Enterprises Educational Coporation.

Evi Karmila \& Yulsafli. (2017). Analisis Diksi dalam Antologi Puisi Karya Ali Hasjmy. Serambi Akademica, 4(2), 81-88.

Hairi Abdullah. (2016). The Power of Muhasabah: Manajemen Hidup Bahagia Dunia Akhirat. Medan: Perdana Publishing.

Hasanah Abd. Khafidz \& Nik Siti Khadijah Nik Salleh. (2016). Penyucian Jiwa

Melalui Pendekatan Muhasabah dalam Penghayatan Shalat. Fikiran Masyarakat, 4(2), 128-134. 
Hashim Awang. (1994). Metodologi Kesusasteraan Islam: Kaedah Penilaian. Dewan Sastera, Februari, 10-15.

Hashim Awang. (1995). "Metodologi Kesusasteraan Islam: Kaedah Penilaian.” S. Jaafar Husin (Ed.), Nadwah Ketakwaan melalui Kreativiti. Kuala Lumpur: Dewan Bahasa dan Pustaka, 30-45.

Hashim Awang. (1998). Teori dan Kritikan Sastera Melayu. (Bahagian Akhir). Dewan Sastera. Oktober, 7-10.

Hashim Awang. (2002). Teori Pengkaedahan Melayu dan Prinsip Penerapannya. Bengkel Teori Sastera anjuran Dewan Bahasa dan Pustaka. Kuala Lumpur di Riviera Bay Resort, Melaka pada 28-29 Jun.

Keraf, Gorys. (1988). Diksi dan Gaya Bahasa. Jakarta: Gramedia.

Keris Mas. (1988). Perbincangan Gaya Bahasa. Kuala Lumpur: Dewan Bahasa dan Pustaka.

Kennedy, X. J. (1983). Literature: An Introduction to Fiction, Poetry, and Drama. Boston: Little Brown and Company.

M. Hariyanto. (2016). Muhasabah (Introspeksi), Akhlak yang Terabaikan. Kertas kerja Pengajian Jumat Petang Ba'da Maghrib, Kajian Hadis Tematik. Anjuran Masjid Margo Rahayu Namburan Kidul Yogyakarta. 25 November.

Muhammad Abdul Jawad. (2004). Menjadi Manajer Sukses. Depok: Gema Insani Press.

Mohd. Ali Hashimi. (1996). Keperibadian Muslim. Kuala Lumpur: Pustaka Salam.

Octavio Paz. (1992). The Other Voice: Essays on Modern Poetry. Boston: Houghton Mifflin Harcourt.

Pradopo, Rachmad Djoko. (2009). Pengkajian Puisi. Yogyakarta: Gajah Mada University Press.

Yudi Martono. (2013). Tinjauan Stilistika dalam Kumpulan Puisi Aku Manusia karya A. Mustofa Bisri. NOSI, 1(7), 812-813.

Zaen Kasturi. (1992). Yuda. Kuala Lumpur: Dewan Bahasa dan Pustaka.

Zaen Kasturi. (1993). Katarsis. Kuala Lumpur: Dewan Bahasa dan Pustaka.

Zaen Kasturi. (1997). Idola. Kuala Lumpur: Sasbadi.

Zaen Kasturi. (1998). Rapsodi. Kuala Lumpur: Dewan Bahasa dan Pustaka.

Zaen Kasturi. (2005). Iga (Kumpulan Puisi). Kuala Lumpur: Dewan Bahasa dan Pustaka.

Zaen Kasturi. (2005). Taman Uzlah. Kuala Lumpur: Dewan Bahasa dan Pustaka.

Zaen Kasturi. (2015). 77 Tuju:Siri Ingatan kepada Kawan. Kuala Lumpur: Institut Terjemahan dan Buku Malaysia.

Zaen Kasturi. (2017). Zamindar (Kumpulan Cerpen). Kuala Lumpur: Institut Terjemahan \& Buku Malaysia (ITBM). 
MALAY LITERATURE VOLUME 33 NUMBER 1 JUNE 2020

Zaen Kasturi. (2020). Fajar Lingkung Lembayung. Kuala Lumpur: Nusa Centre. Zuniar Kamaluddin Mabruri dan Sri Dwi Ratnasari. (2015). Majas dan Citraan dalam Kumpulan Puisi Blues untuk Bonnie Karya W.S. Rendra dan Pemakaiannya. CULTURE, 2(1) Mei, 133-150.

Zurinah Hassan. (2010). Unsur Alam dalam Puisi Melayu Moden. Bangi: Penerbit UKM.

Received: 6 April 2020

Accepted: 25 May 2020 